\title{
Literature Metrology Analysis and Application of Internet Public Opinion
}

\author{
Dan Liu \\ Liabrary, Lingnan Normal University, Zhanjiang, Guangdong, 524048, P. R. China \\ South China Sea Silk Road Collaborative Innovation Centre,Lingnan Normal University \\ liudan100liudan@163.com
}

\begin{abstract}
Keywords: Internet Public Opinions; Internet Guidance; Internet Supervision; Judicial Public Sentiments; Core Poster; Social Issues.
\end{abstract}

\begin{abstract}
At present, the influence of online public opinion is getting increasingly greater. It is very important to grasp the current situation of online public opinion and predict the future development. In order to find out the status of internet public opinion and guide internet public opinion correctly, this paper uses the method of literature metrology to study Internet public opinion. It finds that the research level of "internet public opinion" is not high in the whole, and there is no breakthrough in 10 years, and present the characteristics of the guideline of Internet public opinion and the quality of public opinion on the Internet. Because the Internet can cause that the posts and Microblog related to Internet public opinions have certain characteristics and forms of literature, for example, the poster is like the literature writer and the key words and publishing platform of posted contents are like those of the published journals, some research methods of literature metrology can be directly applied to the Internet posts and Microblog. The paper comes to the conclusion that the government, the traditional media and the VIPs playing the role of leaders of public opinions should act as the core posters, post more posts on two "core journals" (Microblog and Wechat), take part in the discussion of the topic attracting the netizens' attention, and guide the discussion to the positive direction.
\end{abstract}

\section{Introduction}

With the globalization of information, the Internet has become an indispensable part of our lives. Internet public opinion has become the main channel for Internet users to express their own opinions. Internet public opinion also plays an increasingly important role. In recent years, there have been many incidents triggered by cyber media, such as "motor car incident" and "cat abuse incident." Internet public opinion not only has a positive effect on society, but also has negative effects. We should probe deeply into the causes of negative effects and put forward corresponding measures. Eventually, we will achieve the goal of making the Internet public opinion be developed in a rational direction and realize more positive values of online public opinion.

With the prominence of the importance of internet public opinion, there are more and more literatures studying "internet public opinion".

\section{Literature Metrology Analysis of "Internet Public Opinion"}

The paper chooses the literature published from 2001 to 2013. The following Table 1 shows the number of published literature with the CNKI searching subject of "internet public opinion".

Table 1 Number of literature published on "internet public opinions" from 2001 to 2003

\begin{tabular}{l|l|l|l|l|l|l|l|l|l|l|l|l|l}
\hline $\begin{array}{l}\text { Year of } \\
\text { publish }\end{array}$ & $\mathbf{2 0 0 1}$ & $\mathbf{2 0 0 2}$ & $\mathbf{2 0 0 3}$ & $\mathbf{2 0 0 4}$ & $\mathbf{2 0 0 5}$ & $\mathbf{2 0 0 6}$ & $\mathbf{2 0 0 7}$ & $\mathbf{2 0 0 8}$ & $\mathbf{2 0 0 9}$ & $\mathbf{2 0 1 0}$ & $\mathbf{2 0 1 1}$ & $\mathbf{2 0 1 2}$ & $\mathbf{2 0 1 3}$ \\
\hline $\begin{array}{l}\text { Number of } \\
\text { literature }\end{array}$ & 689 & 746 & 874 & 1202 & 1601 & 2268 & 2758 & 3898 & 5521 & 7674 & 9571 & 12522 & 12471 \\
\hline
\end{tabular}

As can be seen from the table, from 2007 onwards, the "online public opinion" discussion of the literature has come into explosive growth, and we can see the online public opinion from 2007 enters a 
fierce state, which is China's first wave of intense state of the Internet. It is also easy to trigger social turmoil and quality defects.

Through CNKI searches for the key words of "internet public opinion", and we can get the discussion key points of "public opinion online" literature, which is sorted in order: internet, college students, microblogging, countermeasures, ideological and political education, internet public sentiments, internet public opinion, new media, Internet, Internet guidance, Internet supervision, public opinion, emergencies. The two key words of "college students" and "ideological and political education" occupy a special top rank. It can be seen that the ideological and political education of the young people such as college students who are the main body of online public opinion has been greatly discussed. The improvement of the ideological quality of young people like college students is a major issue. I think the important means for college students and other young people to improve the quality of public opinion Internet is "Internet supervision" and "Internet guide", so "Internet monitoring" and "Internet guide" the two keywords accounted for higher ranking is also reasonable .

The key words of "online media" are as follows: the number of key word of "Internet guide" is 916, and the number of keyword of "Internet supervision" is 912, which are very close to each other, and they search the number of published literature of "Internet guide" and "Internet supervision". See Table 2.

Table2 Literature on "internet guidance" and "internet supervision" from 2008 to 2013

\begin{tabular}{l|l|l|l|l|l|l}
\hline Year of publish & $\mathbf{2 0 0 8}$ & $\mathbf{2 0 0 9}$ & $\mathbf{2 0 1 0}$ & $\mathbf{2 0 1 1}$ & $\mathbf{2 0 1 2}$ & $\mathbf{2 0 1 3}$ \\
\hline $\begin{array}{l}\text { Literature on } \\
\text { guidance of Internet } \\
\text { public opinions }\end{array}$ & 1373 & 2361 & 3185 & 4142 & 5276 & 5494 \\
\hline $\begin{array}{l}\text { Literature on } \\
\text { supervision of } \\
\begin{array}{l}\text { Internet public } \\
\text { opinions }\end{array}\end{array}$ & 1962 & 2970 & 3949 & 4778 & 5720 & 5717 \\
\hline
\end{tabular}

It can be found that the number of published literature on "Internet public opinion supervision" and the "Internet public opinion guidance" is almost the same quantity each year, that is to say, "Internet public opinion supervision" and the "Internet public opinion guidance" simultaneously develop and influence each other. A good network of public opinion can reduce the pressure of supervision of public opinion on the Internet, and a reasonable supervision of public opinion can provide the direction of Internet public opinion guidance.

Among the authors, Ding Boquan published 74 articles and the number is in the first place, while Chen Lidan published 63 articles which is in the second place. The number of articles written by a single author from the third place to the tenth place was 46, 42, 37, 37, 35, 33, 31, 27. As to the citation of the literature of the high-yielding literature authors, the essay of Ding Boquan with most citation times is Discussion on Public Opinions - and Discussion on the Relationship among it and Public Opinions and News - 68 times. The essay of Chen Lidan with the most citation times is Discussion on Freedom and Control of Internet Public Opinions - 135 times, which is far behind 394 times of quotation of Decisions of CPC on Several Major Issues Including Boosting Cultural System and Promoting the Great Development of Socialist Culture - the most times. Neither the number nor quality of the literature of the high-yielding authors present breaking through recommendations on the supervision and guidance of ideological education of Internet public opinions.

According to the logic of literature information growth, we can calculate the growth rate of literature through Table 1, and deduct that China's online public opinion literature enters into the third phase of the deceleration growth period. At this moment there is no high yield of the author and a large number of high-quality literature, so the fund support is necessary and urgent, in order to increase the fund's support in the field of online media research, to support those high-yield authors, and to encourage high-cited authors of the literature to continue their research. On the other hand, judicial cases accounted for more than half of the top 20 public opinion hotspots in 2013 in the public opinion monitoring room of People's Daily [1], whereas in the keyword search, the judicial rankings are not on 
the top. The number of published articles on the CNKI search topic "Internet Opinion and Justice" is shown in Table 3 below, based on the publication year.

Table 3 Number of Published Literature on "Internet Opinion and Justice" from 2001 to 2013

\begin{tabular}{l|c|c|c|c|c|c|c|c|c|c|c|c|c}
\hline $\begin{array}{l}\text { Year of } \\
\text { publish }\end{array}$ & $\mathbf{2 0 0 1}$ & $\mathbf{2 0 0 2}$ & $\mathbf{2 0 0 3}$ & $\mathbf{2 0 0 4}$ & $\mathbf{2 0 0 5}$ & $\mathbf{2 0 0 6}$ & $\mathbf{2 0 0 7}$ & $\mathbf{2 0 0 8}$ & $\mathbf{2 0 0 9}$ & $\mathbf{2 0 1 0}$ & $\mathbf{2 0 1 1}$ & $\mathbf{2 0 1 2}$ & $\mathbf{2 0 1 3}$ \\
\hline $\begin{array}{l}\text { Number } \\
\text { of } \\
\text { literature }\end{array}$ & 3 & 13 & 16 & 31 & 42 & 65 & 90 & 126 & 276 & 619 & 815 & 1191 & 1102 \\
\hline
\end{tabular}

The "Sun Zhigang case" in 2003 was the first judicial case that the internet public opinion exerted its influence on the judiciary. In 2003, it was also the beginning of the development phase of the influence of the internet public opinions on the judiciary [2]. As can also be seen from the table, the literature on "Internet public opinion and justice" started to accelerate in 2003, but the number published in 2013 decreased and the total number of documents was small. It is not enough to show the research on "internet public opinion and justice". It is foreseeable that the discussion meeting on judiciary public opinion will be greatly increased in 2014, and the fund support organizations should prepare for the advance support and promote the rapid development of judicial research.

Another high-yielding group is colleges and universities. The top 40 research institutions are all universities, and 16 out of top 40 of literature sources are universities. As a participant and researcher in online public opinion, colleges and universities have great ideas and experiences, which are different from those of other agencies only conducting data analysis. Therefore, they can learn from them.

In terms of source of literature, the top ten are "Youth Journalists", "News Enthusiasts", "Journalism and Communication", "Journalism", "Southeast Dissemination", "News Fight Line", "Chinese Journalists", "Today’s Media", "Shandong University" and "News Outpost." Youth Journalists came in first. Because the magazine is a ten-day issue, it is not surprising that the number of published papers is relatively small. However, the average quoted rate of "Young Journalists" is not high, while "News Lovers" and "News Knowledge" are the core national journals; the average citation rate is higher than that of "Young Journalists"[3]. Therefore, "News Lovers" and "News Knowledge" can be listed as core journals. Researchers can refer to both journals. On the other hand, from the names of the top ten journals, it can be found that Internet public opinion has become not only an ordinary Internet issue but a social issue. It is big news. Its essence is the issue of participant's thinking and social ethos. Therefore, researchers should also combine Internet public opinions, social values and social ethos to study, instead of focusing on Internet public opinion alone. The study of social ethos is a breakthrough in improving the quality of public opinion on the Internet.

\section{Application of Literature Metrology Analysis Method to Internet Public Opinions}

The main research object of literature metrology is literature author, periodical and key words. Similarly, the posts that cause the public opinion on the internet, Microblog, etc. have similar places, which are referred to here as: the poster (similar author), the posting platform (similar periodical), the hot words (similar keyword). Therefore, some ideas of literature metrology can be directly applied to Internet public opinion instead of merely inferring the status of Internet public opinion by studying related literature of Internet public opinion. Today, the most posting platform for online discussion is WeChat and Microblog, which is equivalent to the "core periodical". Therefore, the government and traditional media as well as the Internet opinion leaders who are the main body of Internet public opinion supervision and network media guidance should play the role of the core post person more, guide more in these two "core periodicals" (Microblog, WeChat) to facilitate supervision. According to Lotka's law, high-yield authors posts or microblogging sum should account for one-third. It is clear that the current public opinion is still dominated by the grassroots, therefore, the core post should increase posting activity. It calls on all kinds of netizens with professional knowledge, theory and technical background, especially some experts and opinion leaders within the system, to provide professional opinions and positive discussions on Internet topics in professional fields so as to provide netizens with accurate and 
persuasive professional judgment. This is conducive to purifying the Internet public opinion and advocating a public discussion atmosphere of rational science [1]. On the other hand, among ordinary Internet users, negative news is more likely to spread than positive news. The important task of spreading positive energy lies with the government and traditional media and network opinion leaders. For example, in 2013, Internet hotspot was "gang rape lead by the son of Li Shuangiiang" It was negative news. At this time, the government online account should guide public opinion to another positive direction and guide it with positive energy. On the negative news content, if the public opinion lasted too long, it will depress the network environment, which in turn will lead to social depression.

Network hot words are the equivalent of keywords, and most of them are spread by users of the Internet, and therefore users rather than the traditional media choose their own, which can reflect the psychological characteristics of Internet users. The following is a list of the top 10 buzzwords in Chinese competing literary critic magazine Excessive Wording from 2008 to 2013 and arranged in the following order according to the popularity.

2008: copycat, stunning, embarrassing, never abandon and never give up, lipstick effect, turning point, indoorsy, no Z-Turn, Do not bother if you are not pure-hearted;

2009: not in short of money, hide-and-seek, low carbon, be employed, naked, entangled, fishing, second kill, dwelling narrowness, ant tribe.

2010: gelivable, everything is nothing, Microblog, onlookers, second generation, daddy competition, fan, king, talent, traverse.

2011: dear, too delicate to bear a blow, hold, whether you believe it or not, I believe it, kidding, acting cute, trash about, aura, miserable, perturbed

2012: positive energy, "Yuanfang, what's your opinion", on tongue, sneak in the damp hole, tall, rich and handsome, Chinese-style, too much stress, like, most beautiful, grounded

2013: Chinese dream, light disc, reversed transmission of pressure, counterattack, micro XX, network VIP, tough girl, local tyrant, freak, like

2014: "you know" ranks at top

It can be found that the causes of the popularity of these words can be divided into several categories: (1) word personality; (2) social prevalence; (3) reflection of people's livelihood; (4) from major events. From the hot words of the situation we can see the general psychological characteristics of users: the pursuit of individuality, like to use the words of individuality, concerned about the people's livelihood. Therefore, government and traditional media should make more posts or Microblog on people's livelihood or social phenomena when they lead the public opinion on the Internet, and cause netizens to discuss (meaning making comments), and then use personal words to put forward their own opinions on this topic. They should also present their position on the topic with individualized words and guide the netizens, so netizens can accept them more. To give an example: In 2008, "China's ten most influential CCTV columns", "Lectures Room," "the Same Song," "Art of Life", "Animal World" and other CCTV columns are the finalists, so that everyone is surprised that CCTV News with the top audience rating among all CCTV programs is not listed. One of the important reasons is that the contents of CCTV News pay attention to international route and public affairs, and are not close to livelihood. However, in 2013, the Internet influence of CCTV New is at the top because there is an obvious change of subject selection and draws great attention of network media. In terms of discussion among the netizens, the livelihood topics with an increased ratio arouse the sympathy more. In terms of reference on Microblog, CCTV News Microblog, Wechat and user terminal jointly made effort to expand the platform value by fully exerting the characteristics of the social media. In terms of video click, the news item of network-based broadcasts is the most concerned [4].

From the development of hot words, we can see that the proportion of hot words from the government is gradually increasing, and the proportion of positive hot words is also increasing. In 2012 and 2013, a total of five words came from CCTV, reflecting that the quality of online public opinion has been improved and that the CCTV public opinion leader dominated by CCTV News are right.

As mentioned above, judiciary public opinion will become a new hot spot on Internet. The "core posters" should also be prepared in this regard. Especially the People's Courts and other relevant institutions should register the corresponding online platform. People's courts should pay close attention 
to the judicial public opinion and correctly analyze and treat them with tolerance. They can neither indifferently act on the public opinions nor be controlled by the public opinion, and avoid influence on independent and fair trial according to law. As to the inaccurate, incomplete and out of context of judicatory public opinions, they should respond to the concerns promptly by issuing accurate and complete judicial information, clarify the truth and eliminate the public misunderstanding [1]. Relevant persons in charge of judicial cases should also re-analyze the judicial cases that are greatly affected by the public opinion on the Internet, such as the "Yao Jiaxin Case", and analyze whether the trial result is biased due to public opinions to prevent similar deviation in subsequent cases.

\section{Summary}

In the field of research on Internet public opinion, there has not been a breakthrough and no representative researcher. The related fund support should be done. The internet public opinion supervision is synchronized with the internet public opinion guidance. When the guidance is well done, the supervision pressure is reduced. When the supervision is in place, there are directions to guide. On the network platform, all the government agencies such as Microblog, WeChat and the client should work together as the core posters to choose the hot topics for discussion. Judicial public opinion will become the new focus of the future. Internet public opinion is essentially social issues, ideological issues, so research should also look at the community.

\section{Acknowledgements}

It is a pleasure to acknowledge the support of the project from XU Yan-li being selected in the introduction of shortage top talent of "Sailing up (Yangfan) project" in Guangdong Province in 2014. The project is Leading Industry Development Strategy Research in Emerging Areas in Western Guangdong for Accelerating the Economic Development of Western Guangdong.

It is a pleasure to acknowledge the support from the talents introduction project of universities in Guangdong Province and from Guangdong University of Petrochemical Technology. The project is the Coordinating Development Model Construction and the Path Research of Technical Capability and Technology Management Capability in Equipment Manufacturing Industry.

It is a pleasure to acknowledge the support from the talents introduction project of Guangdong University of Petrochemical Technology. The project is Research on the Coordinating Development Model and Path of Technical Capability and Technology Management in Maoming (513088).

It is a pleasure to acknowledge the support from comprehensive reform experiment of the Major of International Economics and Trade in Guangdong University of Petrochemical Technology.

It is a pleasure to acknowledge the support from International Education Department in Guangdong University of Petrochemical Technology. The project is Research on Teaching Quality Evaluation for the Major of International Economics and Trade in English in the Background of International Education (2014GDUPTGJ-07).

It is also a pleasure to acknowledge the support from South China Sea Silk Road Collaborative Innovation Center in Lingnan Normal University (2017EL03).

It is also a pleasure to acknowledge the support from Excellent Course "Macroeconomics" in Teaching Quality and Teaching Reform Project in Lingnan Normal University in 2017 (114961700227).

\section{References}

[1] Trend of Internet Public Opinions and Pattern of Social Public Opinions in 2013[J]. Journalists, 2014(2)

[2] Huang Jiapeng, Influence of Internet Public Opinion Supervision on Judicial Procedures[J] 
[3] Cheng Yanxia, Shao Liqin, Wan Yuehua. Literature Metrology Analysis of Study on Internet Public Opinions in China[J]. Information Exploration, 2012(9)

[4] Discovery of List of Internet Spread Influence of China's TV Programs in the First Half of 2013 http://1118.cctv.com/20130802/104421.shtml 